International Journal of

Health, Medicine and

Nursing Practice

(IJHMNP)

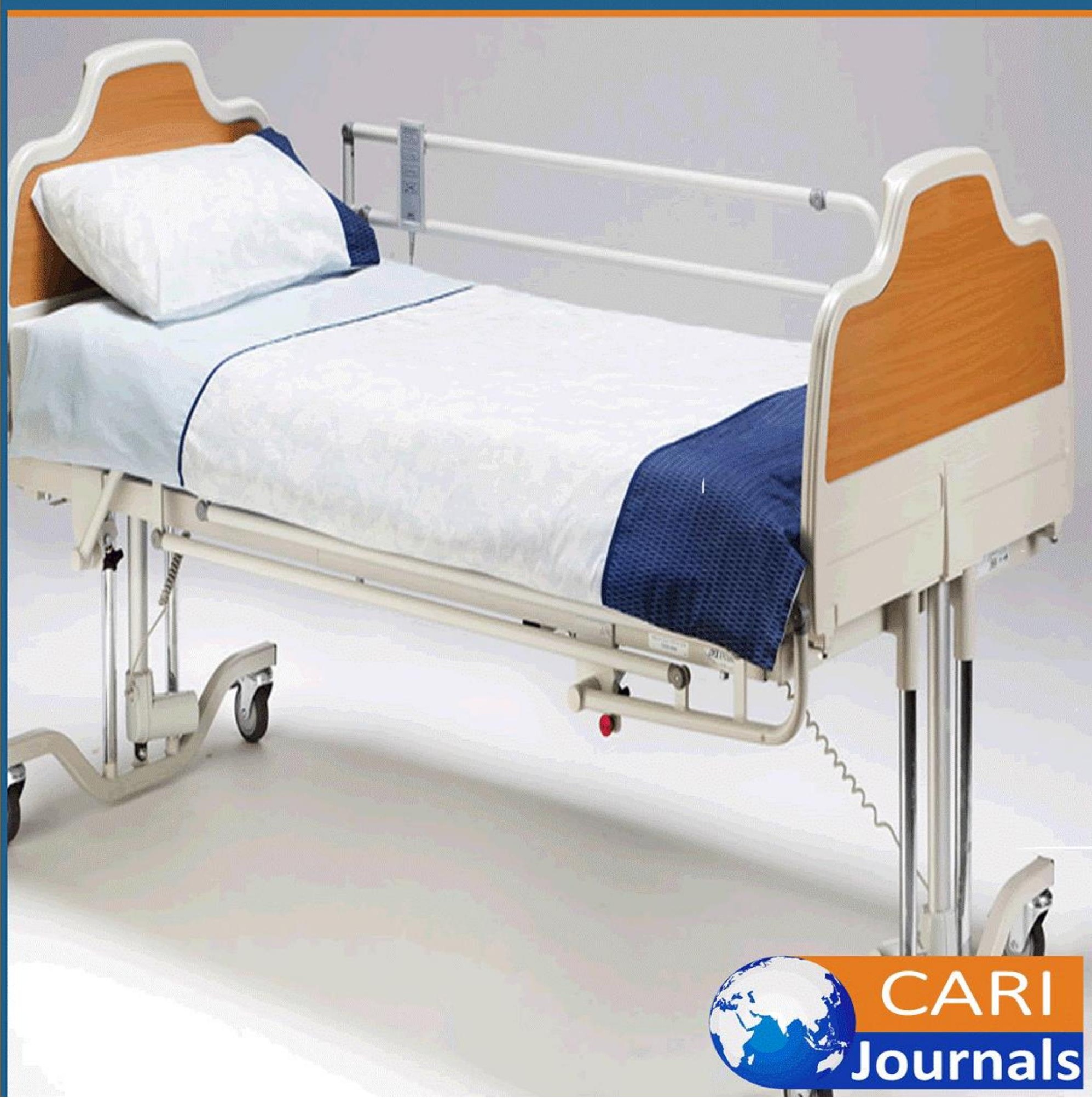




\title{
KNOWLEDGE \& PRACTICE ABOUT ADMINISTRATION OF HIGH ALERT MEDICATION IN THE TERTIARY CARE HOSPITAL IN LAHORE
}

\author{
Ishrat Younis \\ University of Health Science Lahore Pakistan, \\ Sharif City College of Nursing \\ Nabeela Shaheen \\ University of Health Science Lahore Pakistan \\ Sumaira Bano \\ University of Health Science Lahore Pakistan \\ Corresponding Authors E-mail: ishratmichael@gmail.com
}

\begin{abstract}
Purpose: High alert medications are enlightened as those medicines that bear the maximum threat of causing major patient harm when administered incorrectly. Nurses are accountable for the administration of high alert medication; inappropriate administration can show a substantial clinical result and at times can be deadly for the patients. High Alert Medication is commonly used in the emergency room, intensive care unit, pediatric ward and medical ward. Because high alert medication is used in emergency situations, they bear a heightened risk of causing patient harm when used incorrectly. Some high alert medication has a narrow therapeutic index e.g., warfarin, when used improperly, rapidly causes the undesirable side effect of bleeding. Further, well-known chemotherapeutic agents, such as vincristine, require special handling, and should be administered according to the manufacturer's recommendation. Current investigation targeted to evaluate the level of knowledge of high alert medication among nurses in tertiary care hospital. Methodology: A quantitative, descriptive cross-sectional study design was used to explore the level of knowledge and regulations of high alert medication and obstacles faced by nurses during the administration of high alert medication in tertiary care hospital. The instrument used for the data collection was adopted questioner and convenient sampling technique was used.

Results: Outcome of current study deliver confirmation that nurses have deficient knowledge of high alert medication and its administration and regulation. Deficiency of knowledge was the significant obstacles that nurses faced during administration of high alert medication. Participants reported that conflicting views between nurses and doctors, were the most commonly encountered obstacles during administration of high alert medication these contribute to the possibility of Medicine Errors.
\end{abstract}

Key words: High Alert Medication, knowledge, regulations, obstacles 


\section{Background}

Medication error is one of the major concerns of nursing profession. High alert medications are considered to be a greater risk of causing significant harm to patents if used in error. High alert inadequate nurse's knowledge and lack of practice in administration storage and dose calculation increases the risk of medication errors. Medication is commonly used in ER, ICU, C C U ward and medical ward. High alert medication includes insulin heparin warfarin narcotics sedatives and chemotherapy.

\section{Introduction.}

High alert medications (HAMs) are considered to be one which are associated with a high risk of serious harm, if administered improperly, and are responsible for the majority of harmful errors. Nurses are responsible for administration of High Alert Medication (HAMs); incorrect administration can have a significant clinical outcome, and at times can be fatal.

High Alert Medication (HAMs) is commonly used in the emergency room (ER), intensive care unit (ICU), pediatric ward and medical ward. Because High Alert Medication (HAMs) is used in emergency situations, they bear a heightened risk of causing patient harm when used incorrectly. Some High Alert Medication (HAMs) has a narrow therapeutic index e.g., warfarin, when used improperly, rapidly causes the undesirable side effect of bleeding. Further, well-known chemotherapeutic agents, such as vincristine, require special handling, and should be administered according to the manufacturer's recommendation, .(Sa'ed et al., 2019) According to the Institute of Medicine in the USA, adverse drug events occur in 6\%-10\% of all hospitalized patients. When these adverse events involve high-alert medications, patients are at a greater risk of suffering serious harming (Sa'ed et al., 2019). Safe practices during prescribing, dispensing and administration of these medications can reduce the potential harm to patient (Sa'ed et al., 2019)

Intravenous (IV) medication errors are a common type of error .identified in hospitals and can lead to considerable harm. Over the past 20 years there have been several hundred FDA reported incidents involving IV pumps, many of which have led to patient deaths. (Tang et al., 2015) According to the Institute of Medicine, 7,000 deaths each year are attributed to preventable medication errors. The definition of a high-alert medication is a "medication that bears a heightened risk of causing significant patient harm when used in error." This does not imply that errors occur more often with high-severe and even fatal. In the mid1990s, the Institute for Safe Medication Practices (ISMP) examined the drugs that were most likely High alert medications than other medications but rather, when an error does occur, the consequences can be to cause harm to patients.

A review of medication error incidents reported between 2005 and 2010 to the National Reporting and Learning Service indicated that 526,186 such incidents had occurred in England and Wales over this period (Cousins et al 2012). A total of 86,821 (16\%) of these incidents caused actual patient harm, of which $822(0.95 \%)$ resulted in death or severe harm (Cousins et al 2012). The cost to the National Health Service hospital admissions related to medication errors in 2007 was $£ 770$ million and between 1995 and $2007 £ 5$ million was spent on litigation costs (Frontier Economics 2014). In the UK, one third of medication errors occurring in general medical practices related to prescribing errors. Many of these were the result of poor 
communication, particularly with regard to the prescription of antibiotics to which patients are known to be allergic (Patey et al., 2007). Medication errors contribute to adverse events that compromise patient safety and place a large financial burden on health systems (Lo, Yu, Chen, Wang, \& Tang, 2013)

\section{Significance:}

This study will increase knowledge and improve practice among nurses regarding high alert medication. This study will be helpful to improve standard of care among staff nurses. Moreover, this study will support hospital management to maintain and improve strategies regarding medication error.

\section{The purpose of study:}

The purpose of this study is to assess the knowledge and practice of nurses regarding High Alert Medication and their advantage?

\section{Research Questions:}

Do nurses have knowledge regarding high alert medication?

What are the practices about administration of high alert medication among nurses?

\section{Review of literature}

A cross-sectional study was conducted in 2006 in Taiwan during which author evaluated nurses' information of high-alert medications and analyses famed administration errors solely $3 \cdot 6 \%$ of nurses thought of themselves to own sufficient knowledge about high-alert medications, $84 \cdot 6 \%$ hoped to achieve a lot of coaching, and also the leading obstacle reported was short information $(75 \cdot 4 \%)$. a complete of 184 famed administration errors were identified, as well as wrong drug (33•7\%) and wrong dose $(32 \cdot 6 \%) ; 4 \bullet 9 \%$ (nine cases; 9/184) resulted in serious consequences (Hsaio et al., 2010). A study was conducted in 2015, in West Bank, Palestine. The response rate was ninety three. Nurses were found to own scant information concerning HAMs; sixty seven.1\% of participants had a score of but seventieth, with a mean total score of fifty nine. $9 \pm 15.1$, with a p-values $<0.001 .81 .8 \%$ of respondents hoped to get extra coaching. The obstacles reportable were inconsistent opinions between doctors and nurses (37.9\%), and no established customary procedure for HAMs (37.1\%)level of information of HAMs among nurses in government hospitals in geographic area, Palestine. (Sa'ed et al., 2019)

IN 2008 Unit of contractile organ Nursing, University of metropolis, Chapel Alperton Hospital, Leeds, GB study was conducted and also the result show that almost all participants gave satisfactory answers to dose, indications and side-effects however scored very poorly on mechanism of action and drug interactions. General reasons for low response included: (i) absence thanks to long sickness and maternity leave, (ii) knowledge assortment happening within the winter season once the hospital was very busy, implying that some nurses might not have had time to participate and (iii) an enquiry methodology involving interviews. (Ndosi \& Newell, 2010) Medication errors related to IV pumps occur of times, have the potential to cause damage, and are epidemiologically numerous. Sensible pumps are a necessary element of a comprehensive safe medication system. However, presently accessible sensible pumps will 
fail to come up with purposeful enhancements in patient safety till they will be interfaced with alternative systems like the electronic anamnesis, processed prescriber order entry, bar coded medication administration systems, and pharmacy info systems. Future analysis ought to specialize in the effectiveness of recent technology in preventing latent and active errors, and on new sorts of error that any technology will introduce.(Husch et al., 2005)

A study was conducted in Ahmadabad tertiary care hospital Asian country accreted with JCI and NABA to scale back the medication error associated with high alert medication Data of high alert medication errors throughout could 2017 to August 2017 were collected. The proportion of incidence and severity of high alert medication error were known and calculated. (Husch et al., 2005)

\section{Methodology.}

The cross sectional descriptive study design was used in this study. A self-administered questionnaire was distributed among staff nurses of mayo hospital Lahore to assess the KNOWLEDGE AND PRACTICE OF HIGH ALERT MEDICATION .staff nurses of mayo hospital were the target population mainly composed of 157 staff nurses. The inclusion criteria were staff nurses and exclusion were not included the students nurses, trainee, any health professionals. Participants were selected through convenient sampling techniques. Sample size was113 according to solvin's formula sample was consisted of 38 questions including 8from drug aadministration, 8 from regulation 14 from obstacles and remaining from knowledge and training needs. Data analysis by SPS version 21.confidentially and privacy of the participants was considered. The participant were informed about the objectives of the study.

$\mathrm{n}=$ sample size

$\mathrm{N}=$ target population

$\mathrm{E}=$ margin of error

$\mathrm{n}=157 / 1+157(0.05) 2$

$\mathrm{n}=157 / 1+157(0.0025)$

$\mathrm{n}=157 / 1+0.392$

$\mathrm{n}=113$

\section{Results}

\begin{tabular}{|l|l|l|l|}
\hline Profile & & $(f)$ & $\%$ \\
\hline & & & \\
\hline Age & $<25$ Years & 23 & 20.4 \\
\hline & $>25-30$ Years & 54 & 47.8 \\
\hline
\end{tabular}


International Journal of Health, Medicine and Nursing Practice

ISSN 2710-1150 (Online)

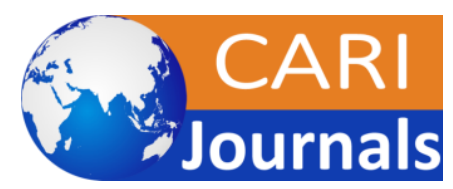

Vol.3, Issue No.4, pp $1-16,2021$

$\underline{\text { www.carijournals.org }}$

\begin{tabular}{|c|c|c|c|}
\hline & $>30-35$ Years & 19 & 16.8 \\
\hline & $>35$ Years & 17 & 15.0 \\
\hline \multirow[t]{2}{*}{ Gender } & Male & 8 & 7.1 \\
\hline & Female & 105 & 92.9 \\
\hline \multirow[t]{3}{*}{ Qualification } & Diploma Nursing & 83 & 73.5 \\
\hline & Bachelors & 22 & 19.5 \\
\hline & Master MSN & 8 & 7.1 \\
\hline \multirow[t]{4}{*}{ Unit Experience } & $<2$ years & 26 & 23.0 \\
\hline & $>2-5$ years & 55 & 48.7 \\
\hline & $>5-10$ years & 22 & 19.5 \\
\hline & $>10$ years & 10 & 8.8 \\
\hline \multirow[t]{2}{*}{ ICU training } & Yes & 67 & 59.3 \\
\hline & No & 46 & 40.7 \\
\hline \multirow[t]{4}{*}{ Job experience } & $<2$ years & 19 & 16.8 \\
\hline & $>2-5$ years & 49 & 43.4 \\
\hline & $>5-10$ years & 25 & 22.1 \\
\hline & $>10$ years & 20 & 17.7 \\
\hline \multirow[t]{2}{*}{ ER training } & Yes & 81 & 71.7 \\
\hline & No & 32 & 28.3 \\
\hline
\end{tabular}

Table No 1: $92.9 \%$ of the respondents' were female and 7.1\% were male

Among 113 participants $(n=23) 20.4 \%$ participants were between <25years, with the mean of 2.27. An entire of 83 (73.5\%) participants were from Diploma Nursing but $(n=22) 19.5 \%$ were in the Bachelors. A total $(n=55) 48.7 \%$ of respondents were $>2-5$ years of unit experience, while $(n=26) 23.0 \%$ were have $<2$ years of unit experience. Almost $(n=67) 59.3$ participants have ICU training. Most of the participant $(n=81) 71.7 \%$ have ER training. 
International Journal of Health, Medicine and Nursing Practice

ISSN 2710-1150 (Online)

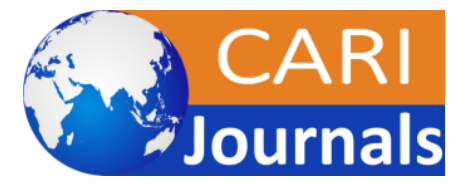

Vol.3, Issue No.4, pp 1 - 16, 2021

www.carijournals.org

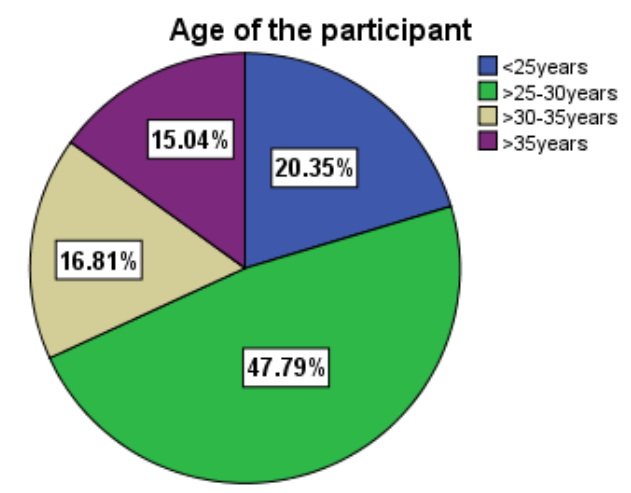

Figure 1

Age of participant:

(Table 4.1) Among 113 participants $(n=23) 20.4 \%$ were between < 25years, $(n=54) 47.8 \%$ participants were between $>25$-30years, $(n=19) 16.8 \%$ were between $>30$-35years, $(n=17)$ $15.0 \%$ were $>35$ years. (Figure 4.1 .1 )

Figure :2

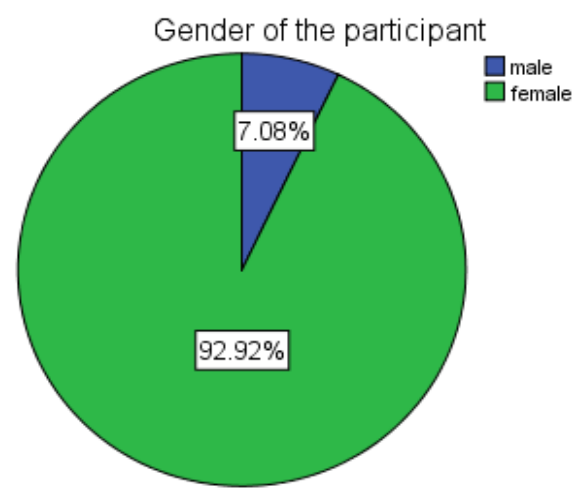

(Table 4.2) Nurses Knowledge about Administration of High Alert Medication

\begin{tabular}{|l|l|l|l|l|}
\hline Variable & $\begin{array}{l}\text { Yes } \\
(\boldsymbol{f}) \%\end{array}$ & $\begin{array}{l}\text { No } \\
(\boldsymbol{f}) \%\end{array}$ & $\begin{array}{l}\text { Don't know } \\
(\boldsymbol{f}) \%\end{array}$ & Mean \& SD \\
\hline $\begin{array}{l}\text { Fast IV pushes 1: 1000 epinephrine 1 } \\
\text { ampule for patient who has mild } \\
\text { allergic reaction. }\end{array}$ & $(81) 71.7 \%$ & $(30) 26.5 \%$ & $(2) 1.8 \%$ & $1.30 \pm .498$ \\
\hline $\begin{array}{l}\text { When an emergency happens, fast IV } \\
\text { push 10\% CaCl2 10mL in 1-2 min }\end{array}$ & $(48) 42.5 \%$ & $(60) 53.1 \%$ & $(5) 4.4 \%$ & $1.62 \pm .572$ \\
\hline $10 \%$ calcium gluconate 10\% Cacl are & $(33) 29.2 \%$ & $(65) 57.5 \%$ & $(15) 13.3 \%$ & $1.84 \pm .635$ \\
\hline
\end{tabular}


International Journal of Health, Medicine and Nursing Practice

ISSN 2710-1150 (Online)

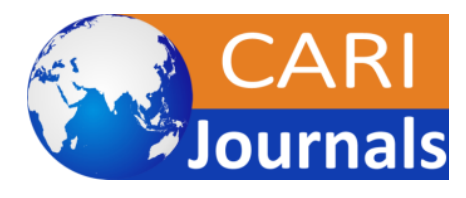

Vol.3, Issue No.4, pp 1 - 16, 2021

www.carijournals.org

\begin{tabular}{|l|l|l|l|l|}
\hline the same drugs and interchangeable. & & & & \\
\hline $\begin{array}{l}\text { Cc and ml are the dosage expression } \\
\text { for insulin injection }\end{array}$ & $(21) 18.6 \%$ & $(79) 69.9 \%$ & $(13) 11.5 \%$ & $1.93 \pm .546$ \\
\hline $\begin{array}{l}\text { Insulin syringe can be replaced by } \\
1 \mathrm{ml} \text { syringe }\end{array}$ & $(44) 38.9 \%$ & $(58) 51.3 \%$ & $(11) 9.7 \%$ & $1.71 \pm .636$ \\
\hline $\begin{array}{l}\text { When an emergency happen such as } \\
\text { ventricular fibrillation, fast 15\% } \\
\text { KCL 10ml given iv }\end{array}$ & $(46) 41.7 \%$ & $(53) 46.9 \%$ & $(13) 11.5 \%$ & $1.71 \pm .666$ \\
\hline $\begin{array}{l}15 \% \text { kcl is better added to ringer } \\
\text { lactate solution for rapid infusion in } \\
\text { case of dehydration }\end{array}$ & $(60) 53.1 \%$ & $(45) 39.8 \%$ & $(8) 7.1 \%$ & $1.54 \pm .627$ \\
\hline $\begin{array}{l}\text { Fast iv infusion of } 3 \% \text { nacl500ml for } \\
\text { patient who has low sodium level }\end{array}$ & $(71) 62.8 \%$ & $(32) 28.3 \%$ & $(10) 8.8 \%$ & $1.46 \pm .655$ \\
\hline
\end{tabular}

(Table 4.2) shows Nurses Knowledge about Administration of High Alert Medication. On asking a question, "Fast IV pushes 1: 1000 epinephrine 1 ampule for patient who has mild allergic reaction", among the respondents' $(n=81) 71.7 \%$ stated Yes, $(n=30) 26.5 \%$ stated No, $(n=2) 1.8 \%$ were answered in don't know with mean and SD of $1.30 \pm .498$. The participants were asked a question "When an emergency happens, fast IV push $10 \% \mathrm{CaCl} 210 \mathrm{~mL}$ in $1-2 \mathrm{~min}$ ", where $(n=48) 42.5 \%$ said Yes, $(n=60) 53.1 \%$ said No, $(n=5) 4.4 \%$ were stated in don't know with mean and SD of $1.62 \pm .572$. On asking a question, "10\% calcium gluconate $10 \% \mathrm{Cacl}$ are the same drugs are interchangeable." among the participants $(n=33) 29.2 \%$ were mentioned Yes, $(n=65) 57.7 \%$ mentioned No, $(n=15) 13.3 \%$ were stated don't know with mean and SD of $1.84 \underline{+} 635$.

Table 4.2 shows Nurses views about a question, "Cc and $\mathrm{ml}$ are the dosage expression for insulin injection", where $(n=21) 18.6 \%$ participants were replied in Yes, $(n=79) 69.9 \%$ were answered in No, $(n=13) 11.5 \%$ were stated don't know. On asking a question, "Insulin syringe can be replaced by $1 \mathrm{ml}$ syringe", among the respondents $(\mathrm{n}=44) 38.9 \%$ were answered in Yes, $(\mathrm{n}=58) 51.3 \%$ stated in No, $(n=11) 9.7 \%$ were mentioned as don't know.

Nurses views about "When an emergency happen such as ventricular fibrillation, fast 15\% KCL $10 \mathrm{ml}$ given IV" Among the participants $(\mathrm{n}=46) 40.7 \%$ stated Yes, $(\mathrm{n}=53) 46.9 \%$ were stated No, $(\mathrm{n}=13) 11.5 \%$ stated don't know with mean $1.71 \pm .666$. In response to another question, " $15 \% \mathrm{kcl}$ is better added to ringer lactate solution for rapid infusion in case of dehydration" the participants responded as below. $(n=60) 53.1 \%$ answered in Yes, $(n=45) 39.8 \%$ answered in No, $(\mathrm{n}=8) 7.1 \%$ were answered in don't know with mean and SD of $1.54 \pm .627$. In response to a question," Fast iv infusion of 3\% nacl500ml for patient who has low sodium level" among the participants $(n=71) 62.8 \%$ stated Yes, $(n=32) 28.3 \%$ were stated No, $(n=10) 8.8 \%$ stated don't know with mean $1.46 \pm .655$. 
International Journal of Health, Medicine and Nursing Practice

ISSN 2710-1150 (Online)

Vol.3, Issue No.4, pp $1-16,2021$

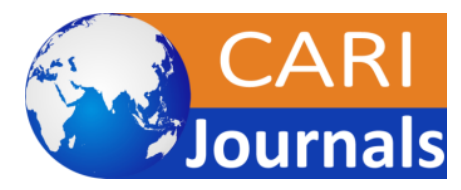

www.carijournals.org

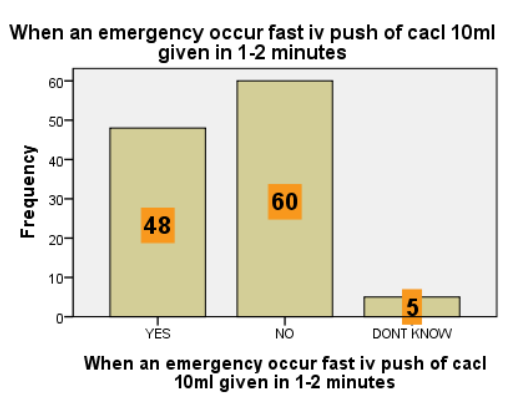

(Figure 4.2.2)

(Table 4.2) When an emergency happens, fast IV push $10 \% \mathrm{CaCl} 210 \mathrm{~mL}$ in $1-2 \mathrm{~min}$ ", where $(n=48) 42.5 \%$ said Yes, $(n=60) 53.1 \%$ said No, $(n=5) 4.4 \%$ were stated in don't know with mean and SD of 1.62 \pm .572 . (Figure 4.2.2)

(Table 4.3) Nurse‘s Knowledge of High Alert Medications Regulation.

\begin{tabular}{|l|l|l|l|l|}
\hline Variable & $\begin{array}{l}\text { Yes } \\
(f) \%\end{array}$ & $\begin{array}{l}\text { No } \\
(f) \%\end{array}$ & $\begin{array}{l}\text { Don't know } \\
(f) \%\end{array}$ & Mean \& SD \\
\hline $\begin{array}{l}\text { Use amp or vial for dose expression } \\
\text { instead of mg or gm. }\end{array}$ & $(72) 63.7 \%$ & $(37) 32.7 \%$ & $(4) 3.5 \%$ & $1.40 \pm .560$ \\
\hline $\begin{array}{l}\text { Use distinctive labeling on lookalike } \\
\text { drugs. }\end{array}$ & $(66) 58.4 \%$ & $(43) 38.1 \%$ & $(4) 3.5 \%$ & $1.45 \pm .567$ \\
\hline $\begin{array}{l}\text { For pediatrics dose use teaspoons for } \\
\text { dose expression. }\end{array}$ & $(62) 54.9 \%$ & $(41) 36.3 \%$ & $(10) 8.8 \%$ & $1.54 \pm .655$ \\
\hline $\begin{array}{l}\text { If patient can tolerate potassium can be } \\
\text { administered orally instead of iv. }\end{array}$ & $(61) 54.0 \%$ & $(39) 34.5 \%$ & $(13) 11.5 \%$ & $1.58 \pm .692$ \\
\hline $\begin{array}{l}\text { Taken fentanyl skin patch as regulated } \\
\text { necrotic. }\end{array}$ & $(42) 37.2 \%$ & $(48) 42.5 \%$ & $(23) 20.4 \%$ & $1.83 \pm .743$ \\
\hline $\begin{array}{l}\text { If a ward stores injection atrium for } \\
\text { tracheal incubation this drugs should } \\
\text { store with others drugs and easily } \\
\text { assessable. }\end{array}$ & $(38) 33.6 \%$ & $(60) 53.1 \%$ & $(15) 13.3 \%$ & $1.80 \pm .657$ \\
\hline $\begin{array}{l}\text { Each drug better have multiple } \\
\text { concentrations for nurse to choose }\end{array}$ & $(56) 49.6 \%$ & $(45) 39.8 \%$ & $(12) 10.6 \%$ & $1.61 \pm .674$ \\
\hline $\begin{array}{l}15 \% k c l \text { is frequently used so it should be } \\
\text { easily accessible for nurses }\end{array}$ & $(49) 43.4 \%$ & $(51) 45.1 \%$ & $(13) 11.5 \%$ & $1.68 \pm .672$ \\
\hline
\end{tabular}


Table 4.3 shows nurses views about knowledge of high alert medications regulation. On a question, 'Use amp or vial for dose expression instead of $\mathrm{mg}$ or gm.' $(\mathrm{n}=72) 63.7 \%$ answered in Yes, $(n=37) 32.7 \%$ stated No, $(n=4) 3.5 \%$ were replied in don't know with mean $1.40 \pm .560$. Another question was asked; 'Use distinctive labeling on lookalike drugs', the responses were as below. Among the participants, $(n=66) 58.4 \%$ were stated in Yes, $(n=43) 38.1 \%$ were stated No, $(n=4) 3.5 \%$ were stated that they don't know with mean $1.45 \pm .567$. In response to another question, "for pediatrics dose use teaspoons for dose expression", the participants responded as below. $(n=62) 54.9 \%$ mentioned Yes, $(n=41) 36.3 \%$ stated as No, $(n=10) 8.8 \%$ were replied with don't know with mean 1.54‥655.

Table 4.3 shows Nurses views about a question, "If patient can tolerate potassium can be administered orally instead of iv", where $(n=61) 54.0 \%$ participants were replied in Yes, $(n=39) 34.5 \%$ were answered in No, $(n=13) 11.5 \%$ were stated don't know with mean and SD of $1.58 \pm .692$. On asking a question, "Taken fentanyl skin patch as regulated necrotic", among the respondents $(n=42) 37.2 \%$ were answered in Yes, $(n=48) 42.5 \%$ stated in No, $(n=23) 20.4 \%$ were mentioned as don't know with mean of $1.83 \pm .743$.

Nurses views about a query "If a ward stores injection atrium for tracheal incubation this drugs should store with others drugs and easily assessable." Among the participants $(n=38) 33.6 \%$ stated Yes, $(n=60) 53.1 \%$ were stated No, $(n=15) 13.3 \%$ stated don't know with mean $1.80 \pm .657$. In response to another question, "Each drug better have multiple concentrations for nurse to choose" the participants responded as below. $(n=56) 49.6 \%$ answered in Yes, $(n=45) 39.8 \%$ answered in No, $(n=12) 10.6 \%$ were answered in don't know with mean and SD of $1.61 \pm .674$. In response to a question," $15 \% \mathrm{kcl}$ is frequently used so it should be easily accessible for nurses" among the participants $(n=49) 43.4 \%$ stated Yes, $(n=51) 45.1 \%$ were stated No, $(n=13) 11.5 \%$ stated don't know with mean 1.68+.672.

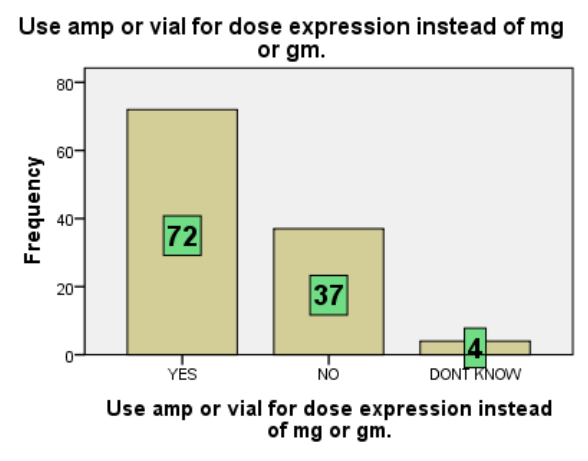

(Figure 4.3.1)

(Table 4.3) Use amp or vial for dose expression instead of mg or gm.' $(n=72) 63.7 \%$ answered in Yes, $(n=37) 32.7 \%$ stated No, $(n=4) 3.5 \%$ were replied in don't know with mean and SD of 1.40+.560. (Figure 4.3.1)

(Table 4.4) Obstacles Faced By Nurses during Administration of High Alert Medication.

\begin{tabular}{|l|l|l|l|}
\hline Obstacles & $\begin{array}{l}\text { Yes } \\
(f) \%\end{array}$ & $\begin{array}{l}\text { No } \\
(f) \%\end{array}$ & Mean \& SD \\
\hline
\end{tabular}


International Journal of Health, Medicine and Nursing Practice

ISSN 2710-1150 (Online)

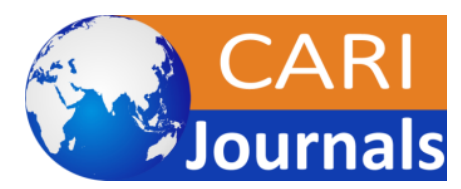

Vol.3, Issue No.4, pp $1-16,2021$

www.carijournals.org

\begin{tabular}{|c|c|c|c|}
\hline $\begin{array}{l}\text { Inconsistent opinions between doctor } \\
\text { and nurse }\end{array}$ & $(72) 63.7 \%$ & $(37) 32.7 \%$ & $1.42 \pm .531$ \\
\hline $\begin{array}{l}\text { No established standard operating } \\
\text { procedures for high alert medication }\end{array}$ & $(53) 46.9 \%$ & $(60) 53.1 \%$ & $1.53 \pm .501$ \\
\hline No reference for drug use & $(42) 37.2 \%$ & $(71) 62.8 \%$ & $1.63 \pm .485$ \\
\hline Have to accept oral order & $(38) 33.6 \%$ & $(75) 66.4 \%$ & $1.66 \pm .475$ \\
\hline Insufficient knowledge & $(45) 39.8 \%$ & $(67) 59.3 \%$ & $1.61 \pm .508$ \\
\hline Confused prescription & $(58) 51.3 \%$ & (54) $47.8 \%$ & $1.50 \pm .520$ \\
\hline Unclear dose calculation & $(53) 46.9 \%$ & $(60) 53.1 \%$ & $1.53 \pm .501$ \\
\hline Find no suitable person to consult & $(51) 45.1 \%$ & $(62) 54.9 \%$ & $1.55 \pm .500$ \\
\hline $\begin{array}{l}\text { Mix high-alert medications with other } \\
\text { drugs }\end{array}$ & $(47) 41.6 \%$ & $(66) 58.4 \%$ & $1.58 \pm .495$ \\
\hline $\begin{array}{l}\text { No rigorous regulations for high-alert } \\
\text { medications }\end{array}$ & $(57) 50.4 \%$ & $(56) 49.6 \%$ & $1.50 \pm .502$ \\
\hline $\begin{array}{l}\text { Receive uncertain answers from } \\
\text { colleagues }\end{array}$ & $(54) 47.8 \%$ & (59) $52.2 \%$ & $1.52 \pm .502$ \\
\hline Inconsistent opinions between nurses & (53) $46.9 \%$ & $(60) 53.1 \%$ & $1.53 \pm .501$ \\
\hline Easy access to high-alert medications & (60)53.1\% & $(53) 46.9 \%$ & $1.49 \pm .536$ \\
\hline Other & (63)55.8\% & $(47) 41.6 \%$ & $1.43 \pm .497$ \\
\hline
\end{tabular}

Table 4.4 is about Obstacles faced by Nurses during Administration of High Alert Medication. On asking a question, Inconsistent opinions between doctor and nurse, where $(n=72) 63.7 \%$ 
respondents were stated yes, $(n=37) 32.7 \%$ stated no with mean and SD of $1.42 \pm .531$. Another question was asked, No established standard operating procedures for high alert medication, among the participants $(n=53) 46.9 \%$ were mentioned yes, $(n=60) 53.1 \%$ were stated no with mean $1.53 \pm .501$. The participants were asked a question, "No reference for drug use", among the respondents' $(n=42) 37.2 \%$ were stated yes, $(n=71) 62.8 \%$ were responded in no with mean $1.63 \pm .485$. Another question asked, "Have to accept oral order", $(n=38) 33.6 \%$ respondents were replied in yes, $(n=75) 66.4 \%$ responded as no. Another question asked to the respondents about Insufficient knowledge, among the participants $(n=45) 39.8 \%$ were stated yes, $(n=67) 59.3 \%$ were stated No with mean of $1.61 \pm .508$.

Nurses views about another obstacle that is "Confused prescription" Among the participants $(n=58) 51.3 \%$ were stated Yes, $(n=54) 47.8 \%$ were stated No, with mean $1.50 \pm .520$. In response to another question from obstacle, "Unclear dose calculation" the participants responded as below. $(n=53) 46.9 \%$ answered in Yes, $(n=60) 53.1 \%$ answered in No, with mean and SD of 1.53 \pm .501 . Participants response about a question, "Find no suitable person to consult", where $(n=51) 45.1 \%$ participants were replied in Yes, $(n=62) 54.9 \%$ were answered in No with mean and SD of $1.55 \pm .500$. On asking a question, "Mix high-alert medications with other drugs", among the respondents $(n=47) 41.6 \%$ were answered in Yes, $(n=66) 58.4 \%$ stated in No, mean of $1.58 \pm .495 .0 n$ asking a question, No rigorous regulations for high-alert medications, $(n=57) 50.4 \%$ respondents were replied in yes, $(n=56) 49.6 \%$ No, with mean of $1.50 \pm .502$.

Table 4.4 shows participants views about Obstacles Faced by Nurses during Administration of High Alert Medication. Findings reveal on asking question "Receive uncertain answers from colleagues" Among the participants $(n=54) 47.8 \%$ mentioned Yes, $(n=59)$ 52.2\% mentioned No, with mean $1.52 \pm .502$. In response to another question "Inconsistent opinions between nurses", the participants responded as below. $(n=53) 46.9 \%$ stated Yes, $(n=60) 53.1 \%$ stated No, with $1.53 \pm .501$. On asking "Easy access to high-alert medications" Among the participants $(\mathrm{n}=60) 53.1 \%$ mentioned Yes, $(\mathrm{n}=53) 46.9 \%$ mentioned No, with mean $1.49 \pm .536$.

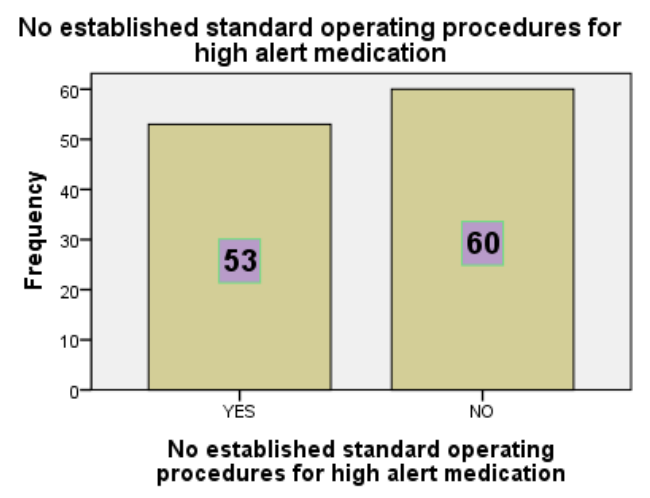

(Figure 4.4.2)

(Table 4.4) No established standard operating procedures for high alert medication, among the participants $(n=53) 46.9 \%$ were mentioned yes, $(n=60) 53.1 \%$ were stated no with mean $1.53 \pm$ .501. (Figure 4.4.2) 
International Journal of Health, Medicine and Nursing Practice

ISSN 2710-1150 (Online)

Vol.3, Issue No.4, pp 1 - 16, 2021

$\underline{\text { www.carijournals.org }}$

\begin{tabular}{|c|c|c|c|}
\hline Level of Knowledge & $\begin{array}{l}\text { Yes } \\
(f) \%\end{array}$ & $\begin{array}{l}\text { No } \\
(f) \%\end{array}$ & Mean \& SD \\
\hline Sufficient knowledge & $(80) 70.8 \%$ & (33) $29.2 \%$ & $1.29 \pm .457$ \\
\hline Relatively sufficient knowledge & $(85) 75.2 \%$ & (28) $24.8 \%$ & $1.25 \pm .434$ \\
\hline Fair enough knowledge & $(73) 64.6 \%$ & $(40) 35.4 \%$ & $1.35 \pm .480$ \\
\hline Insufficient knowledge & $(26) 23.0 \%$ & $(87) 77.0 \%$ & $1.77 \pm .423$ \\
\hline Extremely Insufficient knowledge & $(28) 24.8 \%$ & $(85) 75.2 \%$ & $1.75 \pm .434$ \\
\hline \multicolumn{4}{|l|}{ Training Needs } \\
\hline Need & $(74) 65.5 \%$ & $(38) 33.6 \%$ & $1.35 \pm .499$ \\
\hline No Comment & $(47) 41.6 \%$ & $(65) 57.5 \%$ & $1.59 \pm .511$ \\
\hline No Need & $(36) 31.9 \%$ & $(74) 65.5 \%$ & $1.67 \pm .471$ \\
\hline
\end{tabular}

Table 4.5 is about Self Evaluation, Level of Knowledge and Training Needs For High Alert Medication. Nurses views about a question, "Sufficient knowledge" of high alert medication, where $(n=80) 70.8 \%$ participants were replied in Yes, $(n=33) 29.2 \%$ were answered in No with mean 1.29 \pm .457. On asking a question, "Relatively sufficient knowledge", among the respondents $(n=85) 75.2 \%$ were answered in Yes, $(n=28) 24.8 \%$ stated in No with mean $1.25 \pm$ .434 .

Table 4.5 participants' views about a question "Fair enough knowledge" Among the participants $(n=73) 64.6 \%$ mentioned Yes, $(n=540) 35.4 \%$ mentioned No, with mean $.35 \pm .480$. In response to another question "Insufficient knowledge", the participants responded as below. $(\mathrm{n}=26) 23.0 \%$ 
stated Yes, $(\mathrm{n}=87) 77.0 \%$ stated No, with $1.77 \pm .423$. Participants views on asking "Extremely Insufficient knowledge" Among the participants $(n=28) 24.8 \%$ mentioned Yes, $(n=85) 75.2 \%$ mentioned No, with mean 1.75+.434.

Table 4.5 is also about Training Needs for High Alert Medication. Nurses express their views about a question on training need for high alert medication "Need", $(n=74) 65.5 \%$ respondents were answered in yes, $(n=38) 33.6 \%$ participants responded in No with mean $1.35 \pm .499$. The participants were asked a question, "No Comment", among the respondents' $(n=47) 41.6 \%$ were stated yes, $(n=65) 57.5 \%$ were responded in no with mean $1.59 \pm .511$.

\section{Discussion}

Study about High Alert Medication knowledge aiming nurses who practice wherever in our nation state. We need to assess nurses' awareness and knowledge regarding high alert medication in order to be capable to deliver proper education to bring up-to-date their knowledge, and moreover to avoid any inappropriate management of high risk medications that can put patients' lives in threat. In addition, the knowledge gained from this investigation can be used for establishment of high alert medication for the purpose of guaranteeing accurate and harmless administration, and to eradicate Medicine Errors that can be a reason to harm patients.Graham, Clopp, Kostek, \& Crawford, 2008) The outcomes of this investigation will establish baseline figures about nurses' high alert medication knowledge, so that appropriate educational and training programs can be originated. Furthermore, the outcomes of this education can aid policy makers in academic circles to determine the appropriate courses to offer learners in nursing schools, with respect to the usage and handling of high alert medication.

The response rate in our study was $97 \%$; this is a very adequate answer rate, and is higher than a similar study in Taiwan, which had a response rate of 79.2\%.(Hsaio et al., 2010)

In this research among all the participants $57.2 \%$ participants did not identify that $10 \%$ $\mathrm{CaCl}_{2}$ should not be administered as rapid intravenous push. $\mathrm{CaCl}_{2}$ injection should be administered gradually. Furthermore, it is observed that $70.8 \%$ of participants did not distinguish that $10 \% \mathrm{Ca}$-gluconate and $10 \% \mathrm{CaCl}_{2}$ are not interchangeable. These outcomes established that nurses had insufficient awareness and knowledge about medicines and their administration. These results are similar and somehow greater with the results of another study of Nadosi and fellows who found that $74 \%$ of nurses in the north England had inadequate knowledge. (M. E. Ndosi \& Newell, 2009)

Insulin among the other medicine is most significant high alert medication, as insulin over or low dose due to inadequate high alert medication awareness can lead to fatal outcomes. Usage of insulin syringe for the administration of insulin is very important.(Sa'ed et al., 2019) 38.9\% participants swapped an insulin syringe with $1 \mathrm{~mL}$ syringe. These results are in line with another study done in Palestine by Sa'ed H. Zyoud and colleagues where $32.1 \%$ of nurses replaced an insulin syringe with a $1 \mathrm{~mL}$ syringe. (Sa'ed et al., 2019) It is acknowledged that injection of potassium chloride $(\mathrm{KCl})$ intravenously at extremely high speed can be a reason to cardiac arrest; it has been stated as a reason of death world-wide. (de Melo, Costa, \& Soares, 2014) Supportively, only $41.7 \%$ of participants understood that $15 \%$ potassium chloride $(\mathrm{KCl})$ should not be administered as a fast IV push, although there was a higher proportion of participants who did not identify this. An earlier study have suggested that nurses should not have allowed free 
access to $15 \%$ potassium chloride $(\mathrm{KCl})$ and this medicine should not be kept in nursing units (Lan et al., 2014). It is important to conduct the educational programs for nurses regarding its deadly effects and about its appropriate administration.

Obstacles Faced By Nurses during Administration of High Alert Medication. It is really significant to understand the most frequently faced obstacles that lead the participants to make those mistakes. Results of this study presented that the most common obstacle that are encountered by the participants is when administering high alert medication was conflicting opinions between the nurse and doctor $(n=37) 32.7 \%$. Furthermore, participants responded about Insufficient knowledge, among the participants $(n=45) 39.8 \%$ were agreed that they have insufficient knowledge, $(n=67) 59.3 \%$ were stated No with mean of $1.61 \pm .508$. Nurses views about another obstacle that is "Confused prescription" Among the participants $(\mathrm{n}=58) 51.3 \%$ were stated Yes, $(n=54) 47.8 \%$ were stated No, with mean $1.50 \pm .520$. Results of current study are parallel with the results of another study where conflicting views between the nurse and doctor are $37.9 \%$. Furthermore, $22.9 \%$ of respondents believed that confused prescription was another obstacle. (Sa'ed et al., 2019)

\section{Conclusion:}

Majority of the participants were moderately knowledgeable about Administration of High Alert Medication and its regulations. Outcome of current study deliver confirmation that nurses have deficient knowledge of high alert medication and its administration and regulation. Deficiency of knowledge was the significant obstacles that nurses faced during administration of high alert medication. Participants reported that conflicting views between nurses and doctors, and the lack of established standard operating procedures for high alert medication, were the most commonly encountered obstacles during administration of high alert medication these contribute to the possibility of Medicine Errors.

\section{Limitation and Recommendations:}

- This study was limited to a small population and limited setting where few individuals were studied. The sample cannot be a true representative for large population like province and country therefore cannot be generalized. Such studies need to be conducted on a larger scale.

- We suggest that every hospital should begin its own list of high alert medication and this list should be updated frequently. Every hospital should also establish standard operating procedures (SOPs) for administration and regulation of high alert medication.

- Convenient sampling was applied in data collection process where as the probability sampling method can enhance the induction of different strata of the participants.

\section{REFERENCES}

de Melo, V. V., Costa, M. N., \& Soares, A. Q. (2014). Quality of prescription of high-alert medication and patient safety in pediatric emergency. Farmacia hospitalaria: órgano oficial de expresión científica de la Sociedad Española de Farmacia Hospitalaria, 38(1), 9-17. 
International Journal of Health, Medicine and Nursing Practice

ISSN 2710-1150 (Online)

Vol.3, Issue No.4, pp $1-16,2021$

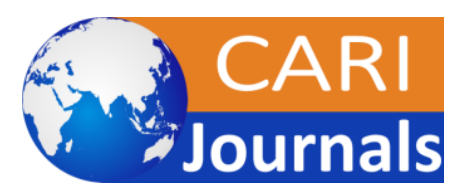

El Enein, N. Y. A., \& Zaghloul, A. A. (2011). Nurses' knowledge of prevention and management of pressure ulcer at a Health Insurance Hospital in Alexandria. International journal of nursing practice, 17(3), 262-268.

Graham, S., Clopp, M. P., Kostek, N. E., \& Crawford, B. (2008). Implementation of a high-alert medication program. The Permanente Journal, 12(2), 15.

Hsaio, G. Y., Chen, I. J., Yu, S., Wei, I. L., Fang, Y. Y., \& Tang, F. I. (2010). Nurses' knowledge of high-alert medications: instrument development and validation. Journal of advanced nursing, 66(1), 177-190.

Hsaio, G. Y., Chen, I. J., Yu, S., Wei, I. L., Fang, Y. Y., \& Tang, F. I. (2010). Nurses' knowledge of high-alert medications: instrument development and validation. Journal of advanced nursing, 66(1), 177-190.

Husch, M., Sullivan, C., Rooney, D., Barnard, C., Fotis, M., Clarke, J., \& Noskin, G. (2005). Insights from the sharp end of intravenous medication errors: implications for infusion pump technology. BMJ Quality \& Safety, 14(2), 80-86.

Husch, M., Sullivan, C., Rooney, D., Barnard, C., Fotis, M., Clarke, J., \& Noskin, G. (2005). Insights from the sharp end of intravenous medication errors: implications for infusion pump technology. BMJ Quality \& Safety, 14(2), 80-86.

Kapadia, N., Raval, S., \& Gadhave, P. (2017). Medication Errors Related to High Alert Medication. J Nurs Health Stud, 2(3), 15.

Lan, Y.-H., Wang, K.-W. K., Yu, S., Chen, I.-J., Wu, H.-F., \& Tang, F.-I. (2014). Medication errors in pediatric nursing: Assessment of nurses' knowledge and analysis of the consequences of errors. Nurse education today, 34(5), 821-828.

Lo, T.-F., Yu, S., Chen, I.-J., Wang, K.-W. K., \& Tang, F.-I. (2013). Faculties' and nurses' perspectives regarding knowledge of high-alert medications. Nurse education today, 33(3), 214-221.

Lo, T.-F., Yu, S., Chen, I.-J., Wang, K.-W. K., \& Tang, F.-I. (2013). Faculties' and nurses' perspectives regarding knowledge of high-alert medications. Nurse education today, 33(3), 214-221.

Ndosi, M. E., \& Newell, R. (2009). Nurses' knowledge of pharmacology behind drugs they commonly administer. Journal of clinical nursing, 18(4), 570-580.

Ndosi, M., \& Newell, R. (2010). Medicine information sources used by nurses at the point of care. Journal of clinical nursing, 19(17-18), 2659-2661.

Ndosi, M., \& Newell, R. (2010). Medicine information sources used by nurses at the point of care. Journal of clinical nursing, 19(17-18), 2659-2661.

Patey, R., Flin, R., Cuthbertson, B. H., MacDonald, L., Mearns, K., Cleland, J., \& Williams, D. (2007). Patient safety: helping medical students understand error in healthcare. BMJ Quality \& Safety, 16(4), 256-259. 
Patey, R., Flin, R., Cuthbertson, B. H., MacDonald, L., Mearns, K., Cleland, J., \& Williams, D. (2007). Patient safety: helping medical students understand error in healthcare. BMJ Quality \& Safety, 16(4), 256-259.

Ramaiah, B., Sharma, S., Poudel, S., \& Koneri, R. (2019). Development and Validation of an Instrument to Enhance the Community Pharmacy Practitioner's Knowledge towards Handling of High Risk/Alert Medications. Global Journal of Medical Research.

Sa'ed, H. Z., Khaled, S. M., Kawasmi, B. M., Habeba, A. M., Hamadneh, A. T., Anabosi, H. H., ... Al-Jabi, S. W. (2019). Knowledge about the administration and regulation of high alert medications among nurses in Palestine: a cross-sectional study. BMC Nursing, $18(1), 11$.

Sa'ed, H. Z., Khaled, S. M., Kawasmi, B. M., Habeba, A. M., Hamadneh, A. T., Anabosi, H. H., ... Al-Jabi, S. W. (2019). Knowledge about the administration and regulation of high alert medications among nurses in Palestine: a cross-sectional study. BMC Nursing, $18(1), 11$.

Tang, S.-f., Wang, X., Zhang, Y., Hou, J., Ji, L., Wang, M.-1., \& Huang, R. (2015). Analysis of high alert medication knowledge of medical staff in Tianjin: A convenient sampling survey in China. Journal of Huazhong University of Science and Technology [Medical Sciences], 35(2), 176-182.

Tang, S.-f., Wang, X., Zhang, Y., Hou, J., Ji, L., Wang, M.-1., \& Huang, R. (2015). Analysis of high alert medication knowledge of medical staff in Tianjin: A convenient sampling survey in China. Journal of Huazhong University of Science and Technology [Medical Sciences], 35(2), 176-182. 